\title{
Uma poética da relaçāo: a conversa infinita entre Édouard Glissant e Michel Leiris
}

\section{A poetic of the relationship: the endless conversation between Édouard Glissant and Michel Leiris}

\section{Gabriela Mitidieri Theophilo}

\section{RESUMO}

Este artigo apresenta uma leitura, em conjunto, de alguns textos dos escritores e etnógrafos Michel Leiris (França 1901-1990) e Édouard Glissant (Martinica, 1928-2011) a partir dos anos 1950. Nesse período Leiris fez estudos nas Antilhas, a pedido da UNESCO, e Glissant tornou-se seu aluno de etnografia na França. A partir de uma leitura inicial dos questionamentos de Leiris nessa década e, em seguida, dos escritos de Glissant, buscou-se demonstrar a intertextualidade entre as obras de ambos, resultante, sobretudo, das apropriações que Glissant estabeleceu dos textos de seu professor. Mais especificamente, foi demonstrado de que modo os conceitos de créolisation e de Relation, em Glissant, fundam-se em diálogo com as ideias de contato e de comunicação em Leiris. Além disso, objetivou-se compreender, nas reflexões de ambos, os usos da noção de carrefour para representar as sociedades antilhanas, considerando-se os impactos teóricos e ético-políticos dessa formulação em suas obras.

\section{PALAVRAS-CHAVE}

Intelectuais; Historiografia caribenha; Literatura.

\section{ABSTRACT}

This article presents a cross-reading of the writings by Michel Leiris (France, 1901-1990) and Édouard Glissant (Martinique, 1928-2011) from the 1950s onwards. It was during this period that Leiris was researching in the Antilles, under UNESCO's auspices, and that Glissant became his Ethnography student in France. Starting from an initial reading of Leiris' inquiries on this decade, and then of Glissant's writings, the aim of this article is to demonstrate the intertextuality between their works, which is a result, above all, of Glissant's appropriations from the texts of his teacher. More specifically, it aims to explore how the conceptions of "créolisation" and "Relation", by Glissant, are based in a dialogue with the ideas of "contact" and "communication", by Leiris. Moreover, it aims to understand the uses of "carrefour", as a representation of the Antillean societies, and the heuristic impact of this concept on their works.

\section{KEYWORDS}

Intellectuals; Caribbean historiography; literature. 
Desde a década de 1970, aproximadamente, o campo dos estudos culturais, dos estudos subalternos e estudos póscoloniais vêm, simultaneamente, promovendo e apontando a desestabilização de paradigmas teóricos e temáticos estabelecidos por uma tradição acadêmica ainda marcadamente eurocêntrica - entendendo Europa como espaço geográfico e cultural detentor de hegemonia na eleição de temas, questões e abordagens, ou de um "privilégio epistêmico", nos termos de Sanjay Seth, bem como centralizador de espaços editoriais e de divulgação científica (SETH 2013, p. 187). Sendo assim, a emergência das vozes pós-coloniais surge, ao mesmo tempo, como reivindicação de descentralização da produção e divulgação de saberes e como proposição de novas perspectivas epistemológicas, marcadas por vivências diaspóricas, identidades ambivalentes e pelo entrecruzamento de fronteiras étnicas, nacionais e linguísticas. Segundo Ramón Grosfoguel, a atual crítica decolonial questiona fundamentalismos, colonialismos e nacionalismos, evitando a fundamentação em abstratos universais e buscando construir-se em diálogos críticos com diferentes projetos epistêmico-ético-políticos, em direção a um mundo pluriversal, comprometido com o rompimento da colonialidade inscrita não apenas nas relações de exploração capital-trabalho e nas relações de dominação centro-periferia, mas, também, na produção de subjetividades e saberes (GROSFOGUEL 2007, p. 212).

As reflexões promovidas no âmbito dos estudos decoloniais impõem, assim, potentes questões teóricas para a teoria da história e para a história da historiografia, na medida em que essa disciplina tem suas convenções e seus princípios epistemológicos enraizados na modernidade europeia. A internalização desses pressupostos, eles mesmos universalizantes, condiciona, portanto, a atualização de formas específicas de representação do passado, associadas a fenômenos próprios dessa modernidade singular. Tal circunstância tende a silenciar assimetrias nos contatos e nas circulações de saberes, povos e culturas, bem como a mascarar os vínculos entre modernidade, capitalismo e conhecimento histórico. Nesse sentido, Dipesh 
Chakrabarty afirmou que a Europa continua atuando como um "referente silencioso" no estudo do conhecimento histórico. De modo similar, em O universalismo europeu, Immanuel Wallerstein procurou demonstrar as associações entre a lógica de dominação capitalista e a produção de um aparato epistemológico europeu pretensamente neutro e desenraizado de sua origem (NICODEMO; PEREIRA; SANTOS 2017, p. 176-177).

Diante dessas questões, os historiadores têm começado a ponderar as relações entre eurocentrismo, etnocentrismo e escrita da história, com seus desdobramentos teóricos e ético-políticos para a história da historiografia. Trata-se de observar esses debates como possibilidade de diversificação do instrumental teórico e conceitual para a escrita da história sem, no entanto, abrir mão de seus marcos disciplinares, mas tensionando-os e transformando-os na defrontação com outras formas de abordagem (NICODEMO; PEREIRA; SANTOS 2017, p. 180). Silvia Cusicanqui e Eduardo Viveiros de Castro são exemplos de autores que, há algum tempo, vêm afirmando a importância da confrontação criativa de diferentes epistemes, que seria necessária não apenas para a compreensão de cosmovisões e modos de vida não ocidentais, mas, principalmente, para a imaginação e construção de novos projetos de futuro (CUSICANQUI; SANTOS 2015; VIVEIROS DE CASTRO 2009). No que concerne à historiografia, especificamente, Sanjay Seth afirma que o confronto com distintos "modos de raciocínio" é fundamental para que "a escrita da história deixe de ser uma prática imperialista e se torne uma prática ética" (NICODEMO; PEREIRA; SANTOS 2017, p. 181).

Édouard Glissant procurou, ao longo de toda a sua trajetória, pensar as condições de produção de uma subjetividade e de uma história antilhanas a partir de categorias que - embora formuladas em diálogo com os debates europeus, considerassem não apenas a diversidade de modos de vida e de cosmovisões presentes na região, mas a própria materialidade do arquipélago em sua relação com o oceano: lugar de passagem, de contatos 
(duradouros e efêmeros, harmônicos e desarmônicos) e de identidades diaspóricas. Esses esforços teóricos culminaram na construção de conceitos como créolisation (remetendo a uma longa tradição de representação da sociedade antilhana), identité-relation, Relation ${ }^{1}$, pensée archipélique, entre outros. Muitos desses conceitos têm sido, atualmente, mobilizados nos debates decoloniais, na medida em que que consideram o lugar geopolítico e corpo-político do sujeito que fala (GROSFOGUEL 2007, p. 213).

As proposições de Michel Leiris, por sua vez, tanto em seu trabalho mais propriamente etnográfico quanto em seu esforço literário de escrita de si, têm sido, aos poucos, retomadas nas ciências humanas e sociais em função de seus questionamentos sobre a própria fundação do campo da etnografia e de sua potência como forma de crítica da modernidade (herança surrealista e, portanto, romântica) (LÖWY 2008, p. 839-840). Trata-se, assim, de dois autores cuja leitura nos força a imaginar formas não violentas de autorrepresentação e de representação do outro. Édouard Glissant foi aluno de etnografia de Leiris no Museu do Homem, na França, entre 1953 e 1954. Nessa mesma década, poucos anos antes, Leiris esteve nas Antilhas a convite da UNESCO, realizando um estudo que buscava contribuir para o programa antirracista dessa instituição, ancorado na ideia de que a região seria um exemplo de "encruzilhada cultural" e de "convivência harmônica entre raças e culturas". A partir de uma leitura dos questionamentos de Leiris nessa década marcados, ao mesmo tempo, pela experiência antilhana, pela herança surrealista e pelo militantismo francês do pós-Guerra -, e dos escritos de Glissant entre 1950 e 1990, que incluem ensaios sobre a obra de Leiris, este artigo pretende demonstrar a intertextualidade dos estudos de ambos - resultante, sobretudo, das apropriações que Glissant estabeleceu dos textos de seu professor. Deseja-se, assim, compreender as articulações entre uma longa tradição de representação das Antilhas (que remonta ao século XIX e que mobilizou o interesse da UNESCO no arquipélago), os usos, na obra de Leiris, das noções de encruzilhada (carrefour), contato e comunicação e alguns dos 
conceitos formulados por Glissant para pensar a experiência antilhana - especialmente os de créolisation e o de Relation.

Sendo assim, este texto encontra-se dividido em três partes. Na primeira parte, foi feita uma leitura das publicações de Leiris resultantes de suas duas viagens às Antilhas, com o objetivo de expor e analisar a formulação e os usos das noções referidas, buscando, ainda, relacioná-los com a trajetória intelectual de seu autor e com o conjunto mais amplo de questões que emergem de suas obras etnográfica e literária. Na segunda parte, há um exame de alguns ensaios que Glissant escreveu sobre Leiris, quando se procura demonstrar os impactos teóricos e ético-políticos das formulações do último na obra do primeiro, a partir de apropriações específicas. Por fim, na terceira e última parte, busca-se expor e observar, por meio de entrevistas e ensaios de Glissant, a elaboração, definição e os usos, também teóricos e ético-políticos, dos conceitos de créolisation e Relation, sempre identificando os eixos de intertextualidade das obras dos dois autores analisados.

\section{Michel Leiris e a UNESCO: representaçōes da sociedade antilhana}

Como se sabe, o imediato pós-Segunda Guerra foi marcado por uma série de empreendimentos científicos e políticos que visavam à defesa da autonomia dos povos e ao combate ao racismo. Com esses propósitos, a partir de 1949, mais especificamente, a UNESCO engajou-se amplamente em um programa intelectual e pedagógico que contou com a colaboração de inúmeros estudiosos de diversas partes do mundo, e que foi colocado em prática, principalmente, por meio da publicação de análises coletivas e individuais sobre os temas mencionados (MAUREL 2007, p. 2-19).

Entre os anos de 1951 e 1952, por exemplo, a UNESCO patrocinou uma série de estudos no Brasil. Desde abril de 1950, o antropólogo Alfred Métraux ocupava a direção do recém-criado "Setor de Relações Raciais" daquela instituição. 
De acordo com Marcos Chor Maio, Métraux e seu principal assistente na função, o antropólogo Ruy Coelho, ambos com pesquisas realizadas sobre índios e negros na América Latina, representaram, a partir daquela data, uma espécie de lobby latino-americano no interior do departamento de ciências sociais. Ainda segundo Maio, as investigações da UNESCO no Brasil "buscavam apresentar ao mundo os detalhes de uma experiência no campo das relações raciais julgada, na época, singular e bem-sucedida, tanto interna quanto externamente". O pesquisador constata que havia, entre os estudiosos envolvidos no projeto, uma espécie de "conhecimento aceito consensualmente como natural", não problemático, de que a sociedade brasileira "viveria sob a égide da cooperação entre as raças". Desse modo, ela poderia tornar-se um exemplo para o restante do mundo, fornecendo "lições de civilização" em matéria de relações raciais (MAIO 2004, p. 144 e 149).

No mesmo ano de 1952, a UNESCO financiou estudos do escritor e etnólogo africanista Michel Leiris nas Antilhas, partindo de razões similares às que motivaram os estudos no Brasil. Diante da "resolução 3.22 do Programa da UNESCO de 1952", que previa produzir um "inventário crítico de métodos e técnicas empregados para facilitar a integração de grupos sociais que não participam plenamente da vida de seu país, seja por motivos étnicos ou culturais", tratava-se de analisar, também, "situações que se poderia considerar felizes, ou seja, aquelas que oferecem poucas fricções ou que evoluem para um estado de equilíbrio ou harmonia" e que poderiam servir, portanto, como modelo para outras sociedades (LEIRIS 1955, p. 6). ${ }^{2}$

Michel Leiris começou sua carreira como escritor em Paris nos anos de 1920, tendo feito parte das discussões do surrealismo literário, nos moldes formulados por André Breton. Em 1929, ele se afastou de Breton e se aproximou de Georges Bataille, trabalhando na revista Documents, que abordava temas na intersecção entre etnografia, literatura e artes. Foi nessa revista que conheceu Marcel Griaule, etnógrafo que o convidou para participar da missão Dakar-Djibouti (1931-1933),

2 - Trata-se do prefácio institucional da UNESCO ao estudo concluído por Leiris. 
primeira grande missão etnográfica francesa nos territórios coloniais africanos. Ao retornar dessa viagem, Leiris começaria seus cursos no Instituto de Etnologia (instituição fundada em 1925 e que remete à profissionalização do trabalho etnográfico na França), especializando-se em África Negra (Cf. THEOPHILO 2016, p. 91-104). Nos anos de 1940 ele atuou, junto a JeanPaul Sartre, por algum tempo, na revista Les Temps Modernes. O que os aproximava, sobretudo, era o interesse comum nas lutas de descolonização africanas, na literatura afroamericana e, consequentemente, no movimento da Négritude, encabeçado por Aimé Césaire, de quem Leiris tornou-se amigo (Cf. SENGHOR 1967). Foi nesse período, e impulsionado pelos debates com Césaire e Sartre, que ele decidiu colocar sua formação e sua condição de intelectual reconhecido a serviço de outros povos em luta por liberdade.

Foi assim que, em 1948, fez uma primeira viagem às Antilhas a convite de Aimé Césaire com o incentivo de Métraux. Proferiu conferências em Martinica, Guadalupe e Haiti, além de redigir um caderno de viagem (ainda inédito), publicar pequenos textos sobre as práticas de vodu no Haiti e produzir um relatório no qual analisava a configuração socioeconômica da população das ilhas, o acesso à educação e a bens culturais, fornecendo, ao final, algumas impressões mais gerais e sugestões para um futuro de (ainda) maior "integração entre as raças" (LEIRIS 1949, p. 341-354).

Em março de 1950, ele proferiu uma conferência na Association des travailleurs scientifiques (section des sciences humaines), denominada L'ethnographe devant le colonialisme. Nessa ocasião, constatava que a disciplina etnográfica tinha se desenvolvido, na França, junto à expansão da dominação colonial nos continentes africano e asiático. O etnógrafo, portanto, financiado pelo Estado colonizador, jamais poderia ficar indiferente aos problemas relacionados a essa realidade. Visto que um trabalho intelectual honesto, segundo Leiris, era também um trabalho de comprometimento ético, um estudioso de populações colonizadas deveria ser o primeiro a atuar como 
"advogado" em defesa dos interesses dessas populações frente às nações colonizadoras - ainda que isso fosse considerado "contra os interesses nacionais" de seu país de origem (LEIRIS 1969 , p. $84-85) .^{3}$

As circunstâncias presentes mostravam, ainda em seus termos, que a etnografia não deveria mais ser associada unicamente ao folclore. Os etnógrafos não poderiam mais iludir-se com a "salvaguarda" de culturas supostamente "intocadas". Pode-se dizer que, para Leiris, havia uma urgência ética naquele momento: estudar e trocar conhecimentos, prioritariamente, com aqueles povos mais brutalmente afetados pela colonização, que buscavam caminhos para a emancipação (LEIRIS 1969, p. 98-103). Outro ponto importante para ele era a troca de conhecimentos que levasse à formação de uma classe intelectual e de etnógrafos africanos. Assim, ele afirmava que o desequilíbrio existente do ponto de vista da produção do conhecimento "falseava a perspectiva" e contribuía para "nos assegurar de nosso orgulho, nossa civilização se encontrando, assim, fora do exame de outras civilizações, para as quais ela dirige seu próprio exame" (LEIRIS 1969, p. 106-107). ${ }^{4}$

Já no ano de 1951, Leiris participaria de um projeto editorial da UNESCO denominado La question raciale devant la science moderne, dirigido por Alfred Métraux, com conferência intitulada Race et civilisation (LEIRIS 1969, p. 10-80). Tratavase da mesma publicação em que Claude Lévi-Strauss publicou Race et histoire. Nesse mesmo ano, republicou e escreveu um novo prefácio para o diário África Fantasma, que foi resultado de sua primeira viagem de campo nos territórios coloniais franceses da África, entre os anos de 1931 e 1933. Nesse prefácio, ele declarava que "não há etnografia nem exotismo que resistam à gravidade das questões postas, no plano social, pela transformação do mundo moderno", e o contato entre os homens só deixaria de "ser um mito", na medida em que houvesse "trabalho em conjunto contra aqueles que, na sociedade capitalista do nosso século $X X$, são os representantes do antigo escravagismo" (LEIRIS 2007, p. 49).
3 - Essa palestra foi publicada pela primeira vez na revista Les Temps Modernes n. 58, année 6, août 1950 , p. 357-374. Posteriormente, Leiris a incluiu no livro Cinq études d'ethnologie. Le racisme et le tiers monde (LEIRIS 1969, p. 83-112). Nesse ínterim, é válido mencionar que manterei, ao longo deste artigo, os vocábulos "etnografia" e "etnógrafo", palavras utilizadas por Leiris para referir-se ao seu ofício, tanto na palestra citada quanto ao longo de toda a sua obra. Sabe-se, porém, que, no campo das ciências sociais, há um amplo debate que distingue os conceitos de etnologia, etnografia e antropologia. Segundo Lévi-Strauss, por exemplo, etnografia, etnologia e antropologia seriam três etapas de uma mesma pesquisa (GONCALVES 2016, p. 252-253).

4 - Traduções de citações em língua estrangeira são de minha autoria, com exceção daquelas retiradas de livros já traduzidos para o português, especificamente, as obras África fantasma e Espelho da tauromaquia (LEIRIS 2007; 2001). 
Em 1952, finalmente, Leiris voltaria às Antilhas, dessa vez por convite direto da UNESCO. Dessa nova temporada, resultou o texto Contacts des civilisations en Martinique et en Guadeloupe (LEIRIS 1955, p. 8). Segundo o prefácio institucional da publicação, as Antilhas seriam um exemplo privilegiado de convivência harmônica entre culturas e raças, ainda que alguns problemas persistissem, como a superposição da repartição de classes e de categorias raciais, "sem que exista, porém, coincidência absoluta". Mesmo que antagonismos "mais de ordem econômica do que racial" perdurassem, o estudo detalhado e objetivo de Michel Leiris mostrara que a igualdade jurídica alcançada por toda a população a partir de 1848 tornara-se uma "fonte inesgotável de progresso". Além disso, os esforços locais e franceses em matéria de instrução possibilitaram "integração suficiente das massas", de modo que já era perceptível "a contribuição original que essas sociedades traziam para a cultura francesa". Ainda nos termos da UNESCO, já se observava, na maior parte da população, uma sensível atenuação dos preconceitos raciais, considerados uma "relíquia da velha época colonial" (LEIRIS 1955, p. 6-7).

A introdução escrita por Leiris, por sua vez, esclarecia que o trabalho que ora se apresentava era resultado de estudo em fontes bibliográficas diversas, de análise de grande parte do material recolhido na primeira viagem que fizera às Antilhas em 1948 e de uma série de entrevistas que conduzira em Paris com franceses originários das ilhas (LEIRIS 1955, p. 8). A viagem de 1948, de acordo com Leiris, teve como objetivo o exame do folclore da Martinica, de Guadalupe e do Haiti ("em busca do que poderia ser considerado como traços de civilização de origem africana") e o estabelecimento de contato com intelectuais das três ilhas, a fim de estreitar os laços culturais tanto com a República do Haiti, quanto com os novos departamentos franceses. Dessa vez, porém, a meta principal era proceder ao "exame crítico dos meios empregados para a integração dos grupos humanos não europeus à vida e à comunidade nacional". O objetivo do estudo era de ordem prática: fornecer dados e sugestões aos governos locais e ao governo francês para a 
implantação de políticas que pudessem contribuir para pôr fim aos preconceitos raciais e para a integração cada vez maior dos povos das Antilhas, de forma que essas sociedades forjadas no "convívio de tradições de origens diversas" pudessem servir de exemplo para o restante do planeta (LEIRIS 1955, p. 8-12).

A conclusão desse texto de 1952 é comedida em comparação à conclusão do relatório de 1948 . Leiris ressalta a continuidade dos cortes socioeconômicos entre raça e classe e prioriza a explicação de ordem econômica: segundo ele, "apenas uma transformação profunda na estrutura econômica das duas ilhas" poderia resolver efetivamente o problema das desigualdades sociais entre "pessoas de cor" e brancos (LEIRIS 1955, p. 178).

Ambos os estudos, de 1952 e de 1948, revelavam a admiração de Michel Leiris pelos intelectuais antilhanos e pelo trabalho que eles empreendiam para a valorização da herança cultural africana e da língua crioula nas ilhas. A percepção idealizada da convivência entre raças e culturas nessa região, porém, ficava mais clara nas páginas finais do artigo escrito em 1948. Em seus termos, os intelectuais antilhanos estavam localizados "na encruzilhada [carrefour] de civilizações as mais diversas" e, desse modo, "em posição privilegiada para a elaboração de um sincretismo de grande estilo, prefiguração parcial do que poderia realizar, desde que essa elaboração se instaure no porvir, a sociedade sem raças. A militância desse grupo junto à parte mais africana da população contribuiria, ainda, para a criação de uma "uma cultura autenticamente 'antilhana'" (LEIRIS 1949, p. 354).

Ao longo dessa primeira viagem, em 25 de outubro de 1948, Leiris proferiu, no Instituto Francês do Haiti, uma conferência denominada Antilles et poésie des carrefours (LEIRIS 1992a, p. 67-87). Para a discussão desenvolvida neste artigo, essa conferência é fundamental, na medida em que, nela, Leiris define sua noção de carrefour e explica os motivos pelos quais escolhera essa palavra para se referir às Antilhas. Nesse ínterim, é válido mencionar que tanto a noção leirisiana de carrefour, quanto a noção de créolisation, elaborada por Glissant, bem 
como o próprio interesse da Unesco nas Antilhas, dialogam com uma longa tradição de interpretação das sociedades antilhanas como sociedades "mestiças". O termo créolisation, de acordo com Jean-Luc Bonniol, teve suas primeiras aparições na língua francesa no final do século XIX, tendo sido resultado de "uma longa trajetória lexical da qual essa inovação tecnológica é o ponto de chegada" (BONNIOL 2013, p. 240). Esse conceito, vindo do campo da linguística, seria apropriado pelas ciências sociais para descrever sociedades caracterizadas por um projeto colonial imposto por nações distantes e marcadas por uma economia de plantation; pelo desaparecimento da população autóctone, de modo que foram povoadas por "estrangeiros"; por terem matriz escravagista e por apresentarem um quadro de confrontação de elementos culturais de origens diversas. O mundo colonial, assim, seria fundado sobre uma dupla violência fundadora (a do genocídio da população indígena e, depois, a diáspora e a escravidão). A conotação positivada do termo, por sua vez, teria emergido no quadro da retórica nacional e anticolonial desenvolvida na América latina no momento das independências, com o surgimento do mito da "nação mestiça" (BONNIOL 2013, p. 240-251). Em Leiris e em Glissant, no entanto, esses conceitos aparecem ressignificados por diferentes aportes teóricos, que os distanciam da ideia de "miscigenação" como "mistura" e se aproximam mais de uma ideia de convivência de contraditórios, intersecção e negociação de forças adversas, como se verá.

Voltando à conferência Antilles et poésie des carrefours, Leiris afirmava que o primeiro esforço seria o de explicar o título escolhido: "é permitido conceber as Antilhas como uma efetiva encruzilhada (carrefour). Lugar de encontro [...] de grupos humanos heterogêneos e de correntes de civilização orientadas nos mais diferentes sentidos" (LEIRIS 1992a, p. 70). No entanto, a ideia de carrefour, em Leiris, foi elaborada antes da experiência nas Antilhas. Essa ideia estabelece uma relação de analogia com outras utilizadas ao longo de toda a sua obra e que remetem ao vocabulário da mística cristã e da "alquimia" dos séculos XV e XVI. Sendo assim, a compreensão da noção 
exige um entendimento dos vários e escorregadios significados de "coincidência de opostos" na literatura mística que circulou na Europa nos referidos séculos, sendo relida pelos ocultistas do século XIX e, também, pelos surrealistas no século XX. O etnógrafo, então, definia carrefour como "ponto de intersecção, pivô de rosa dos ventos ou cruzamento de caminhos que parecem equivaler, no domínio poético, àquilo que era o ponto fixo de que falavam os alquimistas, autêntico Carrefour ele também" (LEIRIS 1992a, p. 71).

Ele continuava afirmando que aquilo que mais o havia emocionado no Haiti foram os rituais do vodu, pois esses rituais poderiam representar uma poesia de "carne e osso", uma espécie de maravilhoso "concretizado". O "teatro vodu" configurava-se, assim, como uma arena na qual "uma longa série de dramas e comédias se sucediam", e todos os gêneros encontravam-se misturados: "violência trágica", "carrefour no qual convergiam, formando uma surpreendente unidade, os elementos mais contraditórios" (LEIRIS 1992a, p. 73-84). Ao final da conferência, alegava que seu objetivo não era fazer uma "apologia do vodu", no sentido de um elogio vazio, mas sugerir de que forma a civilização ocidental poderia aprender com essas culturas (LEIRIS 1992a, p. 85-86).

Ao longo de toda a sua obra etnográfica, Leiris elegeu a afetividade, regida por relações de analogia e identificação, como pressuposto da produção de conhecimento. Essa identificação, porém, só seria possível se se considerasse o outro em sua semelhança com o "si-mesmo", ou, melhor dizendo: se o "simesmo" pudesse tornar-se outro por instantes, de forma a abrir a brecha da verdadeira "comunicação". Para que houvesse comunicação era preciso haver existências singulares, sempre dispostas à abertura para o "fora-de-si".

A tematização das noções de "si-mesmo" e de "fora-desi" são constantes na obra de Leiris. Alcançar os instantes de (des)equilíbrio que lançariam o sujeito hors-de-soi deveria ser, segundo ele, o desejo maior do artista. Apenas nesses instantes de vertigem, a partir de um esforço de mise- 
en-abîme de si-mesmo (performatizado na escrita), uma verdadeira comunicação poderia ser estabelecida. A noção de "comunicação", porém, nunca foi estritamente definida por Leiris. Em seu diário, no ano de 1964, ele afirmou que mobilizava essa palavra de modo "inevitavelmente vago" e que a considerava apenas um "eufemismo para comunhão" (LEIRIS 1992b, p. 600). No texto L'homme sans honneur, de 1938, porém, ele havia escrito algumas notas sobre a noção de "sagrado" (como coincidência de contrários) aproximando-a da ideia de comunicação: "revolução desta contradição aparente pela ideia de sagrado enquanto comunicação: projetar para fora, compartilhar o que se tem de mais íntimo [...] comunicar: isso quer dizer estabelecer verdadeiramente uma relação [rapport]" (LEIRIS 1994, p. 125-126). No ensaio Espelho da tauromaquia, escrito no mesmo ano, Leiris nos fornece, mais uma vez, a imagem de um ponto de intersecção, ou encruzilhada, que projetaria o sujeito para fora-de-si, possibilitando, desse modo, a comunicação. Segundo ele "assim como Deus, coincidência de contrários, segundo Nicolau de Cusa [...] pôde ser patafisicamente definido como 'ponto tangente do zero e do infinito'", existiriam nos vários fatos que constituem o universo "certa espécie de nós, ou ponto críticos, que poderíamos geometricamente representar como lugares onde o homem tangencia o mundo e a si-mesmo" (LEIRIS 2001, p. 11).

Esse movimento de mise-en-relation de si-mesmo - fundado sobre um trabalho de linguagem, segundo análise de Phillipe Lejeune - foi encenado em sua mais longa obra, denominada La Règle du jeu. Essa autobiografia literária, dividida em quatro tomos, foi concebida como "obra total" - na medida em que ele afirmava esperar que o processo de escrita pudesse, finalmente, conjugar vida e literatura, savoir-vivre e savoir-poétique. Um livro concebido como um "todo autônomo, livre, obra aberta, como um perpétuo work in progress, que só a morte pudesse interromper" (LEIRIS 1992b, p. 614). A partir de uma escrita "trançada", ainda de acordo com Lejeune, essa autobiografia era, então, "orientada não para o passado da história, no nível do conteúdo, mas para seu próprio devir" (LEJEUNE 1996, p. 287). 
Em artigo sobre Biffures (tomo I de La Règle du jeu), Emmanuel Levinas afirmou que, nesse texto, Leiris elaborou uma expressão que comportava a impossibilidade de "estar em si" e, como consequência, a insuficiência do sujeito que dispõe de um "mundo dado", lançando-se na escrita, simultaneamente, como sujeito e objeto, numa operação dialética (LEVINAS 1981, p. 62). La Règle du jeu começou a ser escrito na década de 1940. Foi entre os anos de 1940 e de 1950, como dito, que Michel Leiris estreitou vínculos com intelectuais caribenhos, como Aimé Césaire. Nessa mesma época, Glissant se tornaria seu aluno no Museu do Homem. ${ }^{5}$

\section{Michel Leiris e as Antilhas na obra de Glissant: por uma etnografia da relaçāo}

Édouard Glissant nasceu na Martinica no ano de 1928. Em sua juventude, foi amplamente impactado pelo movimento da Négritude e pelos debates surrealistas franceses. Estudou etnografia no Musée de L'Homme, entre 1953 e 1954, tendo Michel Leiris como professor. No que concernia à etnografia até então praticada naquela instituição, Glissant criticava o fato de que, por um lado, exceto por Leiris, os etnógrafos partiam às Antilhas sobretudo em busca da "população indígena", impulsionados pela procura do "puro", do exótico. Desse modo, os "camponeses negros do Caribe", ou seja, a maior parte da população caribenha, por serem filhos da diáspora e herdeiros de um cruzamento de culturas, quase nunca eram considerados "primitivos" o suficiente para serem observados. Por outro lado, os povos caribenhos estavam sempre na condição de "objetos" e quase nunca de "sujeitos" do conhecimento etnográfico. Como estudante de etnografia ele próprio, Glissant não condenava a disciplina, por inteiro, como apenas mais um "discurso colonial": ele acreditava que o simples movimento em direção ao outro já era intrinsecamente positivo. Porém, era não somente necessário, mas urgente, que as populações observadas pudessem "observar em retorno" (KULLBERG 2013, p. 970-971).

A defesa tanto de uma etnografia praticada pelos povos
5 - O Musée de I'Homme, localizado no palais de Chaillot, em Paris, foi inaugurado em 1937 em substituição ao antigo $\mathrm{Mu}-$ sée du Trocadéro. Esse museu foi concebido como um espaço de ensino e pesquisa de etnografia, mas, principalmente, como um instrumento pedagógico para o grande público. Michel Leiris foi pesquisador desse museu durante quase toda a sua vida profissional. Sobre a história dos museus de etnografia na França, ver L'ESTOILE (2010). 
das antigas colônias, quanto do incremento de estudos sobre populações "híbridas", foi resultado de um primeiro diálogo de Glissant com a obra de seu professor Michel Leiris. Ambos os etnógrafos, como foi visto, acreditavam que o cruzamento de culturas encontrado nas Antilhas seria um modelo ou um laboratório para o "mundo do amanhã". Ao longo dos anos, Glissant desenvolveria dois conceitos que também foram, em grande parte, devidos à leitura inicial de Leiris - ainda que, posteriormente, acrescidos de outros diálogos. Trata-se dos conceitos de Relation e de créolisation.

Antes de examinar esses conceitos, é válido que se passe por dois textos que Glissant escreveu sobre a obra de Leiris: um, primeiramente, publicado na revista Les lettres nouvelles, em 1956, intitulado Michel Leiris, ethnographe; e outro, veiculado no livro Traité du tout monde: poétique IV, nos anos de 1990, e denominado Repli et dépli.

O primeiro texto foi, claramente, escrito sob o impacto da leitura dos já citados prefácio de 1951 do livro África fantasma, a palestra sobre a "função do etnógrafo" e do estudo Contacts des civilisations en Martinique et Guadeloupe. Três características das obras literária e etnográfica de Leiris são aí destacadas. Em primeiro lugar, Glissant admira a investigação de si que seu professor desenvolvia tanto em La Règle du jeu, quanto no próprio África fantasma. A "vocação de escritor", que o levava a ser "sincero e rígido em relação a si mesmo", seria fundamental para o exercício da atividade etnográfica, "mais do que qualquer outra, dedicada à busca do outro". Em segundo lugar, importava para Glissant a própria concepção leirisiana de "etnografia", como algo que deveria se tornar um "ofício do contato", muito mais do que uma ciência de observação neutra (GLISSANT 1997a, p. 121 e 126).

Em terceiro, destaca-se a solução proposta por Leiris, tanto no prefácio de seu diário africano, quanto no estudo sobre Martinica e Guadalupe, de desenvolvimento de uma etnografia dos contatos culturais e a solidariedade entre os povos contra seus opressores. Na mesma perspectiva que privilegia o 
contato, Glissant corrobora aquela representação das Antilhas, vista como exemplo privilegiado de "cruzamento de culturas":

Duas temporadas nas Antilhas o reafirmam em sua intenção de dedicar-se aos contatos de civilizações. [...] Toda a etnografia das Antilhas [...] inscreve, no presente, um porvir, pois força a considerar os choques entre culturas e confirma (apesar do racismo que grassa nesses países) que não é utópico conceber o advento, um dia, de uma verdadeira civilização híbrida. [...] aqui a observação porta sobre os contatos, sínteses, choques e harmonias entre culturas. Esse é o sentido da atenção que Leiris dedica às Antilhas: [...] ao incômodo, à distanciação, pode suceder a solidariedade (GLISSANT 1997a, p. 127).

Por fim, Glissant constrói um contundente elogio ao esforço de Leiris em sua busca simultânea pelo "mundo dos outros e pelo porvir comum" e, em seguida, introduz seu próprio conceito de Relation, que seria desenvolvido ao longo de toda a sua obra e que dialoga com usos de Leiris da noção de "comunicação". Em Leiris, como dito, a comunicação só poderia ser verdadeiramente estabelecida a partir do esforço poético de abertura de si para o outro. Nesse sentido, uma "atitude literária", ou poética, em seus termos, seria muito mais eficaz que uma suposta "atitude científica". Compartilhar momentos, ainda que efêmeros, de efetivo diálogo e comunicação exigia um mergulho rimbaudiano na vida do outro. No texto aqui apresentado, assim, as noções de "poética" e de "drama do mundo" referidas por Glissant, costuram-se sensivelmente com a obra de seu professor. Em África Fantasma, frustrado com o imperativo de uma observação neutra das populações da Abissínia em suas relações com o sagrado, Michel Leiris afirmava: "O conhecimento abstrato, para mim, nunca deixará de ser apenas a pior das hipóteses [...]. Tenho necessidade de mergulhar no drama dessas mulheres, tocar seus modos de vida, me banhar na carne viva. Dane-se a etnografia" (LEIRIS 2007, p. 434 e 469). Ao final de seu texto, por sua vez, Glissant, falando de seu lugar de antilhano e ecoando a citação de Leiris, declarava "odiar a etnografia" a cada vez que ela não fertilizava o desejo da relação, "dessa relação: o mundo enfim vivo, sofrido, compartilhado. "O observador atento", que é (ou 
era) o etnógrafo, deverá inscrever-se no drama do mundo [...] deverá viver uma poética (um compartilhamento). Assim, Leiris" (GLISSANT 1997a, p. 128-129).

No segundo texto sobre Michel Leiris, Repli e dépli, Glissant define a etnografia praticada por seu professor como uma "etnografia da relação". Na verdade, a próprio esforço de investigação de si praticado em La Règle du jeu, a partir de uma escrita espiralada e tensa, também é incluída por Glissant como modelo de "etnografia". Em 1955, Michel Butor (assim como faria Emmanuel Levinas, anteriormente citado, anos mais tarde), caracterizava a narrativa de Leiris em La Régle du jeu como "dialética", a partir do diálogo com o "outro", leitor, tomado como interlocutor privilegiado, incorporado aos questionamentos constantes do texto. Essa inserção do outro no texto era, também, de acordo com Butor, um abandono da "arte pela arte", em favor da construção de uma literatura com finalidade edificante. Isso não era afirmado, entretanto, no sentido da busca de algum tipo de "salvação" metafísica, mas no sentido da procura de uma "melhora" ou de uma "cura" moral para a própria vida e para a vida do outro. Sendo assim, ainda segundo Butor, ao longo das páginas de La Règle du jeu era, na verdade, não um "eu", mas um "nós" que despertava, "um grupo de indivíduos não idênticos, mas comparáveis, relacionáveis" (BUTOR 1960, p. 262).

Pode-se dizer que são exatamente essas características que atraem Glissant na obra de Leiris. Voltando, portanto, ao texto Repli et dépli, verifica-se a valorização dessa démarche dialógica e subjetiva tanto em suas autobiografias quanto em sua etnografia. Essa abordagem, que daria espaço aos contatos e passagens entre si mesmo e o outro, é contraposta à uma suposta "consciência universal", que, segundo ele, estaria implícita na abordagem estruturalista. ${ }^{6}$ De acordo com Glissant, para Leiris, "o real é uma totalidade que se trama infinitamente". A paixão do escritor seria, então, descobrir e decifrar essa trama, surpreendendo-se na relação com o outro. O exercício de observação de Leiris era, assim, extremamente "rigoroso" e "objetivo", sem derivar, no entanto, em "suposições teóricas". Em um tempo em que vigia,
6 - o detalhamento da crítica de Glissant ao modelo Lévi-Straussiano, no âmbito de uma disputa entre uma aproximação estruturalista e uma aproximação fenomenológica da etnografia, seria matéria de um artigo à parte. No entanto, a partir das observações de Souleymane Bachir Diagne no artigo Édouard Glissant: I'infinie passion de tramer, pode-se entender melhor o debate que contrapunha uma "consciência universal" (que seria subjacente ao modelo de Lévi-Strauss), a uma "poética do mundo". Segundo Diagne, Glissant recorreria a Leiris para "nos fazer entender melhor aquilo que Husserl teria vislumbrado a partir da leitura de Lévy-Bruhl: o valor da etnografia na medida em que ela se liberta da tentativa de assimilar o "diverso ao mesmo". Instalar-se no "contato de culturas" seria "esposar o movimento", sem ancorar-se no "solo firme de uma gramática universal, pura", mas dando-se a um processo indefinido de "créolisation" (DIAGNE 2014, p. 89-91). Sobre esse tema, há também o texto de Christina Kullberg (Cf. KULLBERG 2013). 
ainda segundo Glissant, uma concepção de "etnologia pura", em busca de sociedades supostas como puras, na pretensão de que se pudesse "reter o essencial de um fato social ou cultural na malha das descrições" e presumindo a compreensão plena de um fenômeno observado - revelando, por fim, as estruturas elementares de toda uma sociedade - a etnografia de Michel Leiris não se quedaria na "tentação do universal generalizante" (GLISSANT 1997b, p. 130-131).

Ao descrever um vai-e-vem entre "si-mesmo" e o "outro", refletindo sobre a própria linguagem, costurando e descosturando eventos, observações, autorreflexões, Michel Leiris, segundo Glissant, tornava-se bem-sucedido na criação de um regime verdadeiramente aberto de linguagem, uma poética da relação: "uma aventura da palavra, um desafio que se expõe, em sua relação fora-dentro, si-mesmo-mundo [...]. A prosa de Leiris é assim, uma meta-prosa que avalia a cada instante seu próprio nível de expressão [...]" (GLISSANT 1997b, p. 134-138).

Toda a obra de Michel Leiris encena um questionamento

\section{Os conceitos de créolisation e Relation em Édouard Glissant e sua intertextualidade com a obra de Michel Leiris}

relativo à própria subjetividade. Como herdeiro das discussões surrealistas e leitor de textos místicos (apropriados de forma particular), o uso das relações de analogia e metáfora na linguagem torna-se instrumento performativo de combate à definição cartesiana de sujeito e à separação, também cartesiana, entre sujeito e objeto. De modo similar, a comunicação, tal como descrita e imaginada ao longo da obra de Leiris, também só é possível a partir da construção de uma subjetividade descontínua, não essencial e não orgulhosa de si. A comunicação também pressupunha uma horizontalidade entre soi-même et l'autre.

Portudo isso, pode-se dizer que a obra de Leiris representava, para Glissant, la pensée archipélique, em contraposição a la 
pensée continentale, representada, por exemplo, por Claude Lévi-Strauss. A partir dessas considerações, podem-se compreender melhor algumas noções fundamentais da obra de Glissant, como as noções de créolisation e de Relation.

Em primeiro lugar, deve-se atentar para a diferença entre créolité, conceito que aparece no manifesto Éloge de la créolité (BERNABÉ; CHAMOISEAU; CONFIANT 1989), escrito em 1989 e inspirado em Glissant, e o conceito de créolisation. Em uma série de entrevistas concedidas a Lise Gauvin, o escritor explica que, em suas obras Le discours antillais e L'intention poétique, a última categoria aparece com frequência. Ele afirma que a créolisation é um "movimento perpétuo de interpenetrabilidade cultural e linguística que não permite que se chegue a uma definição do ser". Segundo Glissant, ainda que o "ser" fosse uma "grande e nobre invenção do ocidente", foi um conceito que desembocou em "toda sorte de sectarismos, de absolutos metafísicos e de fundamentalismos". Era isso, também, que, ainda em seus termos, ele reprovava no movimento da Négritude (sem negar sua clara importância): o impulso para a definição de um "ser". Ele continua declarando que acredita ser preciso dizer que há apenas um "sendo" (I'étant), ou seja, "existências particulares que se correspondem e que entram em conflito", num processo contínuo (GLISSANT 2010, p. 31). Entretanto, para que esse processo se realize plenamente, é necessário equivalência entre as partes: "se, entre os elementos culturais postos em relação, há alguns que são inferiorizados em relação a outros, a créolisation não se realiza verdadeiramente. Ela se faz, mas de um modo bastardo e injusto" (GLISSANT 1996, p. 17).

A créolisation, resultado da Relation, é realizada, portanto, entre elementos diferentes (que não se confundem e não se diluem), mas que são equivalentes em valor. A créolisation não é, assim, uma dissolução de identidades, mas uma comunicação (que pode ser harmônica ou desarmônica) entre subjetividades descontínuas (GLISSANT 2010, p. 39-40). A Relation, então, se opõe aos universais. Trata-se de uma dialética sem síntese: "a Relation nos autoriza a passagem [...] entre todas as diferenças 
do mundo, enquanto o universal [...] tentava abstrair estes diferentes [...] à verdade absoluta do ser. [...] A Relação não é jamais uma diluição de particulares" (GLISSANT 2006, p. 220).

Ambos, Michel Leiris e Édouard Glissant, buscaram

Conclusāo

construir formas não sistemáticas de representação de simesmo e do outro. Seus trabalhos performatizam um miseen-jeu da própria subjetividade, uma forma de dar-se ao diálogo permanente. Ao longo de toda a vida, Leiris afirmou ser poeta e escritor, sendo a etnografia seu "segundo ofício". Essa disciplina the teria fornecido novos instrumentos e métodos, além da possiblidade de uma "ampliação de horizontes" e de contatos reais com outras cosmovisões e formas de vida. As convenções científicas, porém, impediriam, na maior parte das vezes, o estabelecimento de uma verdadeira "comunicação". Ele costumava afirmar que decidira publicar postumamente seu Journal para que, a partir dele, fossem abertas novas janelas de comunicação, para que o diálogo não fosse interrompido pela morte. O comércio de si-mesmo na forma do objeto-livro possibilitava, efetivamente, essa continuidade. A literatura, ou a poesia, como ele asseverou inúmeras vezes, seria o único instrumento capaz de projetar a própria subjetividade numa zona off limits, em que as barreiras entre si-mesmo e o outro pudessem ser interrompidas, ainda que por instantes.

Em sua obra, ainda que muito mais prescritiva do que a de Michel Leiris, Glissant também fará constante exaltação de uma démarche poética, única que permitiria a Relation e a imaginação de novos mundos (GLISSANT 2010, p. 63). Ele preconiza uma poética da relação. Poderíamos acrescentar: preconiza uma poética não apenas como instrumento estético, mas como savoir-vivre, como arte de viver. Sobretudo, como arte de dialogar: "aquilo que é projetado como palavra encontra também um outro múltiplo [...]. Iremos perceber que a poética não é uma arte do sonho ou da ilusão, mas uma maneira $[\ldots]$ 
de conceber a relação entre si-mesmo e o outro e a expressar" (GLISSANT 2010, p. 39-44).

Tanto a obra de Leiris quanto a de Glissant nos forçam a uma "leitura pelas dobras". A própria forma de seus textos nos impele à imaginação de um fora-de-nós, à intuição de novas possibilidades não do "ser", mas do "sendo". A obra de Glissant é mais esperançosa que aquela de seu professor, mas ambas estão ancoradas em um compromisso insistente com a sua contemporaneidade, com os problemas de seus (des)semelhantes.

Pretendeu-se demonstrar, nesse estudo, portanto, as relações entre os conceitos elaborados por Édouard Glissant com a obra de Michel Leiris. Em primeiro lugar, a atração de Glissant pela substituição do "exotismo" pela "solidariedade" como forma de abordagem etnográfica. Nessa mesma perspectiva inclui-se a ideia de contato - não apenas representado na postura do etnógrafo, mas, sobretudo, na valorização das "sociedades do contato". Em segundo lugar, buscou-se demonstrar a intertextualidade entre as noções de comunicação e contato na obra de Leiris e as noções de créolisation e de Relation na obra de Glissant. Trata-se, verdadeiramente, de uma conversa infinita.

\section{REFERÊNCIAS BIBLIOGRÁFICAS}

BERNABÉ, Jean; CHAMOISEAU, Patrick; CONFIANT, Raphaël. Éloge de la créolité. Paris: Gallimard, 1989.

BONNIOL, Jean-Luc. Au prisme de la créolisation. Tentative d'épuisement d'un concept. L'Homme, n. 207-208, p. 237288, 2013.

BUTOR, Michel. Une autobiographie dialectique. In: BUTOR, Michel. Répertoire I. Paris: Éditions Minuit, p. 262-270, 1960. 
CUSICANQUI, Silvia Rivera; SANTOS, Boaventura de Souza. Conversas del mundo. In: SANTOS, Boaventura de Souza. Revueltas de indignación y otras conversas. Bolivia: Proyeto ALICE, 2015.

DE L'ESTOILE, Benoît. Le goût des autres: de l'exposition coloniale aux arts premiers. Paris: Flammarion, 2010.

DIAGNE, Souleymane Bachir. Édouard Glissant: I'infinie passion de tramer. Littérature, $n^{\circ} 174$, p. 88-91, 2014/2.

GLISSANT, Édouard. L'intention poétique II. Paris: Gallimard, 1997a.

. Repli et dépli. In: GLISSANT, Édouard. Traité du tout monde: poétique IV. Paris: Gallimard, p. $128-138,1997 b$.

. L'imaginaire des langues. Entretiens avec Lise Gauvin (1991-2009). Paris: Gallimard, 2010.

. Introduction à une poétique du divers. Paris: Gallimard, 1996.

. Images de I'Être, Lieux de I'Imaginaire, Che vuoi? Regards cliniques sur la loi. Nouvelle série, Revue du cercle freudien, $n^{\circ} 25$, p. 215-225, 2006.

GONÇALVES, Alicia Ferreira. Etnografia, etnologia e teoria antropológica, Revista de Ciências Sociais, no 44, p. 247-261, Janeiro/Junho de 2016.

GROSFOGUEL, Rámon. The epistemic decolonial turn, Cultural studies, 21: 2-3; p. 211-223, 2007.

KULLBERG, Christina. Crossroads poetics. Glissant and ethnography. Callaloo, v. 36, n. 4, p. 968-982, 2013.

LEIRIS, Michel. L'ethnographe devant le colonialisme. In: LEIRIS, Michel. Cinq études d'ethnologie. Le racisme et 
le tiers monde. Paris: Ed. Denoël/Gonthier, 1969.

. L'homme sans honneur. Notes pour le sacré dans la vie quotidienne. Paris: Éditions Jean-Michel Place, 1994.

- Espelho da tauromaquia. Tradução Samuel Titan Jr. São Paulo: Cosac Naify, 2001 [1981 édition française].

África fantasma. Tradução André Pinto Pacheco. São Paulo: Cosac Naify, 2007 [1934, 1951,1981 éditions françaises].

- Perspectives culturelles aux Antilles Françaises et en Haiti, Politique étrangère, 14eannée, n4, p. 341-354, 1949.

- Antilles et poésie des carrefours. In:

LEIRIS, Michel. Zébrage. Paris: Gallimard, p. 67-87, 1992a.

\section{Contacts des civilisations en}

Martinique et en Guadeloupe. Paris: UNESCOGallimard, 1955.

Journal (1922-1989). Paris:

Gallimard, 1992b.

LEJEUNE, Philippe. Michel Leiris: autobiographie et poésie. In: LEJEUNE, Philippe. Le Pacte autobiographique. Paris: Éditions du Seuil, p. 245-307, 1996.

LEVINAS, Emmanuel. La transcendance des mots, L'ire des vents. Autour de Michel Leiris. Paris: Cahiers de littérature, 1981, p. 57-63.

LÖWY, Michael. Carga explosiva: o surrealismo como movimento romântico revolucionário. In: GUINSBURG, J; LEIRNER, Sheila (orgs). O surrealismo. São Paulo: Perspectiva, 2008. 
MAIO, Marcos Chor. Abrindo a "caixa-preta". O projeto Unesco de relações raciais. In: PEIXOTO, Fernanda Arêas; PONTES, Heloisa; SCHWARCS, Lilia Moritz. (Orgs.). Antropologias, histórias, experiências. Belo Horizonte: UFMG, 2004, p. 143-168.

MAUREL, Chloé. La question des races: le programme de I'Unesco, Gradhiva, n. 5, p. 114-131, 2007.

NICODEMO, Thiago Lima; PEREIRA, Mateus Henrique de Faria; DOS SANTOS, Pedro Afonso Cristovão. Historiografia periféricas em perspectiva global ou transnacional: eurocentrismo em questão. Estudos históricos, Rio de Janeiro, v. 30, n. 60, p. 161-186, 2017.

SENGHOR, Leopold. Qu'est-ce que la négritude? Études françaises, v. 3, n. 1, p. 3-20, 1967.

SETH, Sanjay. Razão ou raciocínio? Clio ou Shiva? História da historiografia. Ouro Preto, n. 11, p. 173-189, 2013.

THEOPHILO, Gabriela. "Construtor de espelhos": os ofícios do escritor e do etnógrafo para Michel Leiris (1920-1980). Tese (Doutorado em história social). Programa de pós-graduação em história social, Instituto de história, Universidade Federal do Rio de Janeiro, Rio de Janeiro, 2016.

VIVEIROS DECASTRO, Eduardo. Métaphysiques cannibales. Paris: Presses Universitaires de France, 2009.

\section{AGRADECIMENTOS E INFORMAÇŌES}

Gabriela Mitidieri Theophilo 